\title{
A hipercontemporaneidade ensanguentada em Ana Paula Maia
}

\author{
Bloodstained hyper contemporaneity in Ana Paula Maia
}

Ricardo Araújo Barberena

Pontifícia Universidade Católica do Rio Grande do Sul - Porto Alegre - Rio Grande do Sul - Brasil

$\diamond$

Resumo: A trilogia de Ana Paula Maia, composta por Entre rinhas de cachorros e porcos abatidos, $O$ trabalho sujo dos outros e Carvão animal, descreve cruelmente um grupo de personagens, situados num espaço caracterizado pela subalternidade, humilhação e exclusão social. Através de uma escritura pulp, Ana Paula Maia apresenta uma série de imagens abjetas que tematizam uma polpa de sangue, bichos, violência e esgoto. Alijados do status quo, esses habitantes dos subterrâneos da nossa sociedade, enquanto seres-refugo, desperdiçam as suas vidas fazendo o trabalho sujo para-os-outros. Brutalizadas e coisificadas, essas identidades marginais divertem-se pendurando porcos em ganchos ou contemplando os cães dilacerando-se. Esses homens-de-rinha esperam, sob um calor sufocante do subúrbio, a parte carnosa do real que está urdida sob a égide do resto mutilado do cotidiano: os pedaços dos corpos, dos porcos, dos cães, das esperanças.

Palavras-chave: Literatura contemporânea; Hipermodernidade; Pulp fiction; Identidade

Abstract: The trilogy of Ana Paula Maia, composed of Entre rinhas de cachorros e porcos abatidos, O trabalho sujo dos outros and Carvão animal describes a group of characters set in a space characterized by subordination, humiliation and social exclusion. Through pulp writing, Ana Paula Maia presents a series of abject images whose theme a pulp of blood, animals, violence and sewage. Priced out of the status quo, these inhabitants of the society underground, living as scrap, waste their lives doing the dirty work for others. Brutalized and objectified, these marginal identities have fun hanging pigs in hooks or contemplating dogs tearing each other up. These men - of - baiting expect, under a sweltering suburb, the fleshy part of real that is woven under the aegis of mangled rest of the everyday: the pieces of bodies, pigs, dogs, hopes.

Keywords: Contemporary literature; Hyper contemporaneity; Pulp fiction; Identity

Epígrafe-mordente:

"Deve-se entrar em si armado até os dentes"

(Paul Valéry)

"Até os meus dentes me mordem"

(Frase de uma redação de supletivo que eu corrigi. Não sei precisar a data e o autor. Apenas a sua força lírica

que atravessa o pátio da minha memória)

"No fim tudo o que resta são os dentes"

(Ana Paula Maia) 
Hipermercado, hiperpotência, hiperterrorismo, hipertexto, hiperclasse, hiperconsumo. $\mathrm{O}$ que mais não é hiper? O que levará a contemporaneidade à potência superlativa? O que, paradoxalmente, terá deixado o indivíduo hipercontemporâneo numa condição "mais frágil que nunca, na medida em que as obrigações o definem são mais vastas e mais pesadas" (LIPOVETSKY, 2004, p. 9)? Em cruel contradição, vislumbra-se uma trágica existência catastrofista que deriva dos escombros da modernidade. Ao vivermos sob a égide do gigantismo hipernarcísico, buscamos satisfazer falsas sensações de fluidez e flexibilidade que celebrem o aqui-agora. A partir dessa sociedade de consumo, urdida sob o signo do excesso, exacerba-se um rol de produtos, marcas e serviços, disseminados numa vertiginosa galáxia de fluxos numéricos (milhões de sites, bilhões de páginas, trilhões de caracteres, multidões em férias, aglomerações urbanas). A realidade parece estar superpovoada e asfixiada por temporalidades divergentes e tentaculares, alimentadas por um desejo de um "tudo já" e de um just in time. Do gozo à angústia, vivemos uma era do vazio na qual a sedução e a alienação caminham juntas face a uma espécie de hedonismo individual. $\mathrm{O}$ ritmo hipermoderno desagrega questões humanas fundamentais, preconizando-se uma competição de falsas aptidões de transcendência e perenidade comercial. Comandado por um cinismo generalizado, o indivíduo procrastina frente às responsabilidades de valores democráticos. Talvez estejamos vivendo então um determinado niilismo moral, matizado pelo fascínio da frivolidade dos comportamentos políticos e sociais. Alimentado por rações de conforto e felicidade, o egoísmo privado evidencia a derrocada de um coletivismo pluralista. E não se trata de enunciar o óbito da modernidade, mas, sim, o seu remate na forma de um liberalismo globalizado e de uma mercantilização quase generalizada dos modos de vida. A escala do "sempre mais" não encontra limites ao longo dos frenesis consumistas. Numa escala funcional e técnica, edifica-se o hiperindividualismo de um homo oeconomicus, balizado pela maximização dos ganhos sistemáticos. Mesmo que exista um clima de epílogo iluminista, prossegue um sentimento de "fuga para adiante", de modernização desenfreada, "feita de mercantilização proliferativa, de desregulamentação econômica, de ímpeto técnicocientífico, cujos efeitos são tão carregados de perigos quanto de promessas" (LIPOVETSKY, 2004, p. 56). Tendo em vista esse cenário de abandono do espírito crítico, o futuro da hipermodernidade depende unicamente "de sua capacidade de fazer a ética da responsabilidade triunfar sobre os comportamentos irresponsáveis" (LIPOVETSKY, 2004, p. 62). Como já é sabido, o consumo das famílias impulsiona o crescimento das nações desenvolvidas. Em outras palavras, diríamos que não existe desenvolvimento econômico sem hedonismo consumidor. E não cessamos de vivenciar esses efeitos no cotidiano. Proliferam-se as ofertas de um hiperconsumo estetizado nas suas múltiplas naturezas: design, gadgets, jogos, modas, decoração de interiores, produtos cosméticos, spas, cirurgias estéticas. Ávido por descobertas, o sujeito hipercontemporâneo transformou o turismo na principal indústria no mundo (de acordo com a Organização Mundial de Turismo, os 900 milhões de viajantes internacionais representam $12 \%$ do PIB mundial). Nunca se consumiu tanta música, tanto concerto, tantas séries de televisão, filmes e festivais ( 2 mil festivais a cada ano na França). O consumidor se mostra faminto de novidades, animações, espetáculos, experiências emocionais, fruições sensíveis. Estaríamos frente a um consumidor estético? Teria a arte a capacidade de humanizar um tempo regido pelos avatares financeiros?

Nesse sentido, resta a nós retomarmos um conceito de ethos contemporâneo para que possamos estabelecer alguns elementos de uma hipercontemporaneidade. Dessa forma, irrevogavelmente, façamos a primeira indagação: o que é o contemporâneo? Segundo Agamben, a sensibilidade contemporânea mantém fixo "o olhar no seu tempo, para nele perceber não as luzes, mas o escuro" (AGAMBEN, 2009, p. 63). Ou seja: "Todos os tempos são, para quem deles experimenta contemporaneidade, obscuros. Contemporâneo é, justamente, aquele que sabe ver essa obscuridade, que é capaz de escrever mergulhando a pena nas trevas do presente" (AGAMBEN, 2009, p. 63). Já num primeiro flanco teórico emerge um questionamento nodal: o que significa "ver as trevas", “perceber o escuro?” Ver no escuro não significa não-ver.

Os neurofisiologistas nos dizem que a ausência de luz desinibe uma série de células periféricas da retina, ditas precisamente off-cells, que entram em atividade e produzem aquelas espécie particular de visão que chamamos o escuro. $\mathrm{O}$ escuro não é, portanto, um conceito privativo, a simples ausência da luz, algo como uma não-visão, mas o resultado da atividade das off-cells, um produto da nossa retina (AGAMBEN, 2009, p. 63).

A partir da ativação de células periféricas, estamos capacitados a certas travessias que deflagram um habitar o escuro da contemporaneidade. Como passeadores noturnos, nós, contemporâneos, devemos exercitar uma habilidade particular que busca neutralizar as luzes que provêm da nossa época para descobrir as suas trevas. Segundo a inquietante hipótese de Agamben, é possível definir de contemporâneo apenas quem não se deixa cegar pelas luzes do século e consegue entrever nessas a parte da sombra. Ao navegar por essa perversa obscuridade, o passageiro contemporâneo é aquele que percebe o escuro do seu tempo como algo que lhe concerne e não cessa de 
interpelá-lo, pois "contemporâneo é aquele que recebe em pleno rosto o facho de trevas que provém do seu tempo" (AGAMBEN, 2009, p. 60). Pensado nesses termos, o contemporâneo não é mais declinado sob a égide da arbitrariedade sincrônica que pode ser orquestrada conforme as demandas epistêmicas e discursivas. $\mathrm{Ou}$ seja: o contemporâneo ora inicia no pós-segunda guerra mundial, ora começa na virada do século XXI, ora inaugura-se após o medievalismo.

Nessa oscilante promiscuidade temporal, a contemporaneidade se transforma numa substância disforme que se encaixa nas infinitas caixas de aço de poder/saber ficcionalizado nos múltiplos enredos de conhecimento. No entanto, se partirmos de uma neurofisiologia da contemporaneidade, não estaremos preocupados com retalhamentos temporais e periodizações fundacionais, mas, sim, com a potencialidade de um mirar-atravésdo-sombrio da margem, do remoto, do subalterno, do ex-cêntrico. Por isso os contemporâneos "são raros" (AGAMBEN, 2009, p.59). E aqui também eles se aproximam ao próprio conceito de antimodernos, pois, diferentemente ao fascínio pelos "avanços" da modernidade, questionam o seu tempo: "Os antimodernos não seriam outros senão os modernos, os verdadeiros modernos, aqueles que o moderno não engana, aqueles que sabem" (COMPAGNON, 2011, p. 12). De uma forma ou de outra, esses escritores contemporâneos não se iludem com o canto do cisne da modernidade.

Ser contemporâneo é, antes de tudo, uma "questão de coragem" (AGAMBEN, 2009, p. 59) porque significa ser capaz não apenas de manter fixo o olhar no escuro da época, mas também de perceber nesse escuro uma luz que, dirigida para nós, distancia-se infinitamente de nós. Confrontada essa leitura do contemporâneo enquanto ethos em relação à tradicional concepção temporal já bastante questionada pelo seu caráter anárquico e obtuso, instaura-se uma problematização central: de quem sou contemporâneo? Para Roland Barthes, numa anotação incidental, "o contemporâneo é o intempestivo" (apud AGAMBEN, 2009, p. 58). A contemporaneidade seria uma singular relação com o próprio tempo, que adere a este, ao mesmo tempo, dele toma distâncias, mas precisamente, essa é a relação com o tempo que a este adere através de uma dissociação e um anacronismo. Aqueles que coincidem plenamente com sua época não são contemporâneos, pois, em termos neurofisiológicos, têm uma incapacidade de ativação das células off-cells quando é preciso caminhar por espaços de pouca luminosidade.

Alinhado a este conceito de contemporâneo, como seria, então, a sua versão superlativa? Como podemos caracterizar o hipercontemporâneo? Em primeira instância, a resiliência hipercontemporânea se configura por uma necessidade/capacidade de deambular por áreas cobertas "pelas nuvens escuras". Longe da "descompressão cool do ciclo social pós-moderno", agora, torna-se urgente um mergulho na escuridão dos lugares esquecidos, das identidades subjugadas, das amnésias institucionais. Pensado nesses termos, o contemporâneo, na sua versão hiper, seria justamente a potencialização da percepção dos refugos e detritos do tempo presente. Alguém que decide mirar o que está situado em áreas de desamparo. Cabe relembrar aqui o livro A Bibliotecária de Auschwitz, de Antonio Iturbe, no qual é abordada a história de uma garota de quatorze anos, que, no maior e mais cruel campo de concentração nazista, consegue guardar livros e transformálos em janelas no meio da mais terrível escuridão. Munida de livros, a personagem busca uma centelha de esperança por intermédio de narrativas que possam sobrepujar a rotina de extermínio. A epígrafe desse romance, retirada da obra de William Faulkner, talvez seja a melhor definição para que se descreva essa faculdade hipercontemporânea, alinhada ao conceito de contemporaneidade de Giorgio Agamben: "O que a literatura faz é o mesmo que acender um fósforo no campo no meio da noite. Um fósforo não ilumina quase nada, mas nos permite ver quanta escuridão existe ao redor". Com sua escritura-ponto-de-luz, os hipercontemporâneos trazem a escuridão para o desafio do nosso olhar. Afinal, não são todos que tem a vontade de revelar a noite do nosso tempo. E é exatamente no tocante a esse olhar-na-penumbra que inserimos a estética de Ana Paula Maia. Desconforto. Talvez seja essa a melhor palavra para definir metonimicamente a novela Entre rinhas de cachorros e porcos abatidos. Ao longo dos doze capítulos, inicialmente publicados na internet, esse folhetim pulp apresenta a brutalidade abjeta de um cotidiano cruel e sujo que não suporta espaços de lirismo e redenção. Sob o inóspito calor dos abatedouros do subúrbio carioca, Edgar Wilson e Gerson penduram porcos em ganchos enquanto esperam que as rinhas de cães comecem para que possam ter um "verdadeiro" momento de divertimento. Os dois seres-besta se comportam como máquinas desumanizadas que dividem o seu dia em dois momentos pontuais: matar os porcos e ver os cães se matarem. O único divertimento está transformado em rito-de-morte no qual o dilaceramento dos animais acaba se metaforizando como uma triste paródia da própria mundanidade subalterna e nadificada. Nas mandíbulas dos cachorros, sublima-se um ato de mastigar a pedregosa miséria que não permite sonhar com melhores dias. Esses dois brutamontes, que pouco falam e pouco sentem, convertem-se em refugos humanos que esperam muito pouco da vida. Quanto ao ambiente do frigorífero, torna-se bastante explícita a simbologia do porco enquanto animal que vive na sujeira e nunca olha para cima. E é justamente na construção dessa alteridade animal que surge um terrível paralelismo identitário. Afinal, como os porcos, os dois personagens vivem no lixo e numa área onde as 
táticas de amnésia social são presentificadas através do não reconhecimento dos valores daqueles que transitam na periferia.

Acostumados com o esquelético colchão e com a rala comida no prato, esses habitantes de uma identidade nacional clandestina têm poucas forças para olhar para cima na busca de saída reparadora, epifânica e salvacionista. Aos seus olhos resta apenas o triste espetáculo de uma polpa de sangue, tripas e excremento. A vulgarização da morte é percebida em diferentes momentos da novela, mas é no episódio do "resgate" do rim da irmã que a violência assume contornos nauseantes. Ao "reconquistar" o seu rim, Gerson não terá nenhum constrangimento em esfaquear a sua irmã, mas tal atitude será insuficiente porque o seu pai distraído não perceberá que cometeu um pequeno engano:

- Eu não tô nada bem - diz Gerson preocupado. Meu mijo ta secando.

- E o teu rim que tava com tua irmã? Tá onde?

- Deixei no congelador até achar a porra de um médico que o colocasse no lugar e meu pai fritou ele com cebolas e comeu enquanto assistia ao jogo Ipiranga $X$ Uberlândia com mais dois amigos.

- Eles comeram o teu rim?

- É o que to dizendo. Chego em casa tá lá o velho fedido barrigudo comendo o meu rim com cebolas e tomando cerveja. Achei melhor não dizer nada. Eles pensaram que era fígado de boi. O velho é nojento, você sabe (MAIA, 2009, p. 55).

Essa cena absurdista exemplifica a animalização humana no tocante à perda absoluta de afetos, pois o destrinchar dos porcos não se mostra distante das lacerações e profanações do corpo humano. Rasgar a carne da irmã é imprescindível. Digerir o rim do filho (e da filha) com cebolas é um mero descuido. $\mathrm{O}$ desossar dos porcos, dos cães e das pessoas estabelece uma perigosa vertigem na qual as lascas mutiladas se intercambiam sem que haja uma hierarquização entre os pedaços-do-humano e os pedaços-do-animal. Essa massa carnosa desafia a própria centralidade logocêntrica, teatralizando-se uma sombria circularidade do sacrifício das rações de carne-viva: os cadáveres são jogados aos cães, os porcos são lançados aos cães, os cães são arremessados aos cães, os porcos digerem os restos dos restos, os restos humanos devorados pelos porcos, pelos cães e pelo pai. É essa deformidade digestiva que marca essa comunidade distópica de bichos humanos, bichos escrotos (porcos) e bichos bárbaros (cães de rinha). Ao naturalizar a violência, a novela se articula através de uma escritura excessiva que hiperboliza uma retórica do sangue e das tripas na qual imagens ignóbeis são fetichizadas como uma forma de linguagem carnavalizada. A aberração - ou o (a)normal - se transforma em norma de conduta num ambiente onde não restam mais separações entre a razão e a brutalidade. Fica apenas uma pasta de fígados, rins, tripas, porcos, pessoas. A partir dessa poética da identidade abjeta, a escritora começa a expandir o banco de figurações nacionais. Esse mecanismo de reativação de áreas lacunares na negociação de uma brasilidade é capaz de reapresentar uma funesta história na esfera de circulação dos bens simbólicos. Quando essa realidade execrada e excluída se abre à visitação, concretiza-se mais uma experiência que evidencia o ato de decifrar uma mensagem simbólica abandonada, todo aquele texto subliminar se transforma em imagens que magicizam um tempo-espaço particular. No interior da abertura daquele novo canal de imagem, os leitores começam um longo [e lento] processo de (des)arquivar os espelhos de identidade clandestina. Assim, o sujeito excluído é um caminho duplamente subversivo no tocante à materialização de uma realidade antes desmaterializada pelas estratégias de regulamentação da memória nacional.

Segundo Beatriz Resende, essa polpa de carne moída é representada por intermédio de uma textualidade aderente: "Do folhetim traz um grude, um arrebatamento especial, e é pulp no sentido em que o cinema Tarantino é pulp. O volume de sangue circulando é de similar nível" (RESENDE, 2008, p.98). Cabe lembrar que o conceito de "pulp fiction" é derivado das pulp magazines dos Estados Unidos da primeira década do século XX, assim denominadas pelo baixo custo do papel (produzido a partir de polpa de celulose) em que elas eram impressas. Além disso, as pulp magazines, fonte de entretenimento que provia todo o tipo de narrativa, incluindo Faroeste, Espionagem, Guerra, Aventura, Erótico e mais, foram responsáveis ainda pela criação dos gêneros Ficção Científica e Policial Noir (Hardboiled Detective).

A escrita pulp de Ana Paula Maia carrega esse desejo de ser digerida rapidamente. Mas não podemos deixar de mencionar os momentos em que se percebe uma reflexão identitária sobre a pertença subalterna das personagens:

Cão de rinha é um cão que não teve escolha. Ele aprendeu desde pequeno o que o seu dono ensinou. Podem ser reconhecidos pelas orelhas curtas ou amputadas e pelas cicatrizes, pontos e lacerações. Não tiveram escolhas. Exatamente como Edgar Wilson, que foi adestrado desde muito pequeno, matando coelhos e rãs. Que carrega algumas cicatrizes pelos braços, pescoço e peito. São tantos riscos e suturas na pele que não se lembra onde conseguiu a metade. Porém a marca da violência e resistência à morte de outros animais nunca tiraram o brilho de seus olhos quando contempla um céu limpo. Dia ou noite, ele passa boa parte do seu tempo olhando para cima. Quem sabe espera que alguma coisa aconteça no céu ou com o céu. Talvez queira retalhar algumas nuvens com seu facão. Apesar de ter sido criado feito cão de rinha, aprendeu que isso é melhor do que ser um porco (MAIA, 2009, p. 46). 
$\mathrm{Na}$ trajetória de Edgar Wilson se evidencia a melancólica jornada de um sujeito assujeitado pelas suas não-escolhas de existir. Crivados por amputações, o "homem-de-rinha" e o cão-de-rinha são tristes espectros identitários. Ambos são marcados pelas cicatrizes. E como adverte Hannibal Lecter, ao ser consultado sobre as possíveis pistas que ajudem a desvendar o nome de um terrível assassino em série, "as cicatrizes lembram que o passado foi real". Depois de tantas marcas indeléveis na carne, a personagem não sabe mais reordenar a estrutura causal que explicaria o seu script de existência. O corpo está embrutecido desde a tenra idade quando ele foi educado a matar coelhos e rãs. Homem e animal unidos por uma derradeira contingência: "não tiveram escolhas" (MAIA, 2009, p. 44). Ao trabalhador sobra unicamente a capacidade de olhar cegamente para o céu. Um olhar que apenas vê, mas não repara ${ }^{1}$. Não há como reparar aquela rotina de sangue e abjeção. Assim como não há como ser reparado pelos demais membros da sociedade. E é nessa territorialidade de cegueira social que transitam esses seres coisificados.

Publicada juntamente com Entre rinha de cachorros e porcos abatidos, a novela $O$ trabalho sujo dos outros, dividida em sete capítulos, também tematiza a rotina de homens absolutamente à margem do status quo. Habitantes de um subterrâneo social, as personagens principais recolem o lixo, quebram o asfalto, desentopem o esgoto. Eles fazem o trabalho sujo que ninguém quer fazer. Erasmo Wagner recolhe o lixo numa cidade onde "tudo se transforma em lixo" (MAIA, 2009, p. 91). O seu irmão, Alandelon, despedaça blocos de pavimentação há seis anos, sofrendo com a surdez gerada pelo som estridente das britadeiras. E a terceira personagem, Edivardes, desobstrui latrinas, canos, fossas e todos os lugares para onde escoa a imundície da cidade. Anônimos e invisíveis aos olhos das outridades, as três personagens constituem uma espécie de ratos-humanos que se ocupam das sobras rejeitadas e dos restos abundantes. Novamente percebemos uma brutalização humana na qual o grotesco se mostra naturalizado na própria carne do homemrefugo: "Sua vida não é um lixo. Sua vida é muito lixo. Seu olfato está impregnado com o aroma do podre. Seu cheiro é azedo, suas unhas imundas e sua barba crespa e falhada é suja. Ninguém gosta muito de Erasmo Wagner" (MAIA, 2009, p. 92). O lixeiro é representado como um ser que-presta-para-limpar-a-sujeira-dos-outros. Mesmo sofrendo com a tuberculose e o tétano, ele está acostumado a colecionar "o que não presta pra ninguém" e serve "apenas para os urubus, ratos, cães, e para gente como ele" (MAIA, 2009, p.91). Mais uma vez notamos

\footnotetext{
Na epígrafe de Ensaio sobre a Cegueira, de José Saramago: "Se podes olhar, vê. Se podes ver, repara". SARAMAGO, José, Ensaio sobre a Cegueira, São Paulo, Companhia das Letras, 1995.
}

um assustador paralelismo entre o humano e os ignóbeis animais.

Educado no mundo disforme dos dejetos, Erasmo Wagner reconhece o conteúdo de alguns sacos somente pelo cheiro, formato e peso. E é neste estado de completo abandono que a personagem "prefere os urubus, os ratos e a imundície, porque isso ele conhece" (MAIA, 2009, p.91). Como o seu cheiro afasta as pessoas para bem longe, o lixeiro se aproxima somente da sua namorada, Suzete, que é faxineira de banheiro público, e, por isso, "cheira a mijo, bosta e pinho" (MAIA, 2009, p. 93). Impregnados do cheiro-do-dejeto-dos-outros, o casal exala a profunda podridão que nasce naqueles tenebrosos lugares da (des)memória social. Na rua os únicos parceiros de jornada são os cães que disputam cada pedaço despedaçado de qualquer coisa: "Erasmo Wagner corre para apanhar um saco de lixo que caiu na rua. Chuta um vira-lata que abocanhou uma cabeça de galinha. $\mathrm{O}$ bicho foge grunhindo sem largar o pedaço de carne podre" (MAIA, 2009, p. 94). Edivardes, primo de Erasmo Wagner, desentope fossas sépticas, poço de recalque, caixa de decantação, caixa de gordura, ralos e pias. Ou seja: "chafurda mais na imundície que os porcos" (MAIA, 2009, p.94). Como se fossem sísifos imundos e apodrecidos, os primos recomeçam a cada dia o mesmo trabalho de limpar o que foi sujado, de empurrar o que foi deixado, de retirar o que foi olvidado. $\mathrm{O}$ lixeiro acaba se apiedando do seu primo, pois a proximidade com os excrementos ainda é maior na sua fétida realidade: "Meu primo Edivardes trabalha desentupindo esgoto. Isso é um trabalho de merda. Você precisa ver o esgoto das áreas mais ricas. Ele diz que é uma bosta densa" (MAIA, 2009 , p. 94). Não há um instante de suspiro para exercitar a esperança e os falíveis sonhos futuros, porque quando chove a situação piora ainda mais para Erasmo Wagner ao se deparar com o lixo mais azedo do que o normal e com as fezes dos mendigos e dos cachorros por toda parte. É preciso sobreviver àquela forma viver. Resistir ao resto do Outro. Mas mesmo que estejam embrutecidos existem caros episódios heroicos na novela. O que ocorrerá na cena em que Erasmo Wagner salva a vida de um idoso, prestes a ser devorado por um pitt bull feroz:

Puxa o cão contra seu próprio corpo e rolam pelo chão. Ele grita para o motorista ligar a esmagadora. (...) Erasmo Wagner abraça o cão pelas costas. Corre para o caminhão. A esmagadora está pronta para mastigar detritos e ossos caninos. Ele joga o cão lá dentro e consegue desenterrar seu canivete de estimação do pescoço da besta-fera pouco antes de a esmagadora arriar. Pedaços do cão são devorados e regurgitados. O sangue e um pouco de tripa espirram em Erasmo Wagner. Ele limpa o rosto com as costas da mão. As entranhas da besta fedem a carniça. Depois de tudo, Erasmo Wagner precisará tomar mais cuidado pra não ser devorado pelos ratos e urubus (MAIA, 2009, p. 97). 
Se analisarmos o excerto acima, notaremos que, até nesse raro fragmento no qual o ethos humano apresenta protagonismo, o imaginário grotesco se faz presente na referência às tripas, ao sangue, à carniça, aos ratos, aos pedaços de cão. A engrenagem narrativa de Ana Paula Maia parece depender de um emprego descomunal - talvez óbvio e demasiadamente consumível - de símbolos crus que possam ser moídos já numa primeira leitura. Do blog e do folhetim, possivelmente tenha permanecido, enquanto artesania eletrônica, uma frenética vontade de consolidar cenas que sejam impactantes, em termos imagéticos, e devoráveis hermeneuticamente. Se de alguma forma a escritora carioca pode ser refém da velocidade da cognoscibilidade pulp, salienta-se sobremaneira o projeto mimético de buscar a representação da (ex)centricidade do homem-dejeto, do indivíduo exilado na sua própria cidade, do alienígena social.

A partir do detalhamento do ser/estar dos personagens marginalizados, o conteúdo destas narrativas está assinalado enquanto paisagens identitárias antagônicas ao tradicional nacionalismo conjugado num bloco de poder declinado sob figurações nacionais hegemônicas. Tal projeto estético pressupõe um compromisso representacional que coloque em xeque as representações da nação enquanto reflexos de uma superestrutura amarrada por construções políticas, culturais, raciais, linguísticas monolíticas. Mas essa nação que se move através da sua diferença cultural não deve ser confundida como uma forma de absolutizar a alteridade por intermédio de um aglomerado pluralista e apolítico. O que está em jogo, na representação de sujeitos de tamanha subalternidade social, não é um relativismo que oblitere as relações reais de poder em nome de uma noção nivelada de multiplicidade na qual todos se caracterizam como "outros", pertencentes a um grupo minoritário qualquer. Ao buscar iluminar estes sujeitos nacionais sujos, as novelas propõem releitura de uma identidade nacional não mais orquestrada por um sentido de brasilidade pura. À medida que se admite que o sujeito nacional possa ser não-masculino, não-branco, não-burguês, abre-se um leque crítico para revisitar as crises e os combates de uma cotidianidade marcada por várias esferas de poder e por múltiplos pertencimentos identitários. Há, portanto, que se notar como o imaginário abjeto deflagra uma estratégia de narrativização para reificar uma dada identidade agenciada num lúgubre espaço de exclusão dos matizes nacionais. $\mathrm{E}$ isto quer dizer várias coisas: além de projetar uma narrativa excessiva para mimetizar o humano brutalizado, a escritura de Maia busca uma investigação no tocante à catastrófica velocidade de uma linguagem do sangue.

E é no interior desta gramática do exagero que surgirão duas perguntas trucidantes: Esses sujeitos sujos fazem parte da nossa nação? Fazem parte do nosso cotidiano? Afinal, na tradição literária brasileira, personagens como Edivardes, Erasmo Wagner e Gerson se metamorfoseiam em estereótipos, cunhados sob a égide das essencializações psíquicas e políticas. O discurso estereotipificado caracteriza-se como uma forma de representação que rejeita a alteridade e nega o intercâmbio da diferença como um diálogo entre um Eu e um Outro. A autoridade desse discurso se encontra permeada por uma duplicidade discriminatória psíquico-discursiva, acarretando numa estratégia de individualização e marginalização vinculada a um estereótipo nacional: o malandro, o favelado, o sambista. Daí fica uma indagação: ao descrever a pobreza entre tripas, porcos e ratos, Maia estaria repetindo um cacoete naturalista e determinista através de uma ontologia da periferia fétida? Talvez essa indagação não tenha resposta nesse momento. Mas para responder essa pergunta proponho outra pergunta: Pode o subalterno falar? E para essa provocação Gayatri Spivak sentencia que "o subalterno não pode falar". Assim sendo, é preciso que consideremos a mediação pulp como uma forma de linguagem violentada que não está inocentada por postiçamente traduzir um idioma daqueles que não têm voz. Trata-se de ocupar o lugar da outridade e fazer-ela-falar-por-uma-enunciação-alheia. Se não há voz do subalterno, materializa-se uma amputação representacional quanto ao locus autoral.

Curioso é o caso do personagem Alandelon, em $O$ trabalho sujo dos outros, que começa a perder a audição: "Alandelon quebra asfaltos há seis anos. Seu corpo está talhado e rígido, assim como seu cérebro sempre foi: embrutecido. Ele é irmão caçula de Erasmo Wagner" (MAIA, 2009, p. 10). Ironicamente, ou tristemente, o seu nome, que é uma homenagem ao astro francês de olhos azuis, soa dissonante perante um corpo malcheiroso e abrutalhado. Esse personagem, quase surdo, tem sérias dificuldades de ouvir e ser ouvido. E a metaforicidade da perda da audição parece bastante significativa. Há algo na escuta, no entanto, que marcaria a situação fantasmática do viver-juntos com mais propriedade do que a visão. Nas comunidades contemporâneas, seria a escuta que determinaria a vida idílica imaginada por Roland Barthes (2003, p.54), pois o traço da escuta tem como uma das propriedades o poder de demarcar o território. Os espaços são experimentados não unicamente pela visão, mas pela audição. Enquanto rede polifônica de ruídos familiares, o território passa a ser entendido como um reconhecimento dos sinais sonoros. Nesse sentido, Alandelon se torna incapaz de escutar a materialidade familiar, pois a pessoa conhece pelos sons o que lhe pertence. É quase impossível dissociar essa definição de uma sensação de "segurança" e conforto. Ruídos conhecidos não nos trazem preocupações, diferentemente de ruídos desconhecidos, 
que nos obrigam a um trabalho hermenêutico: o que este ruído representa? A perda da escuta acaba representando analogamente um lento silenciamento do mundo hostil que o circunda, restando apenas os blocos a serem quebrados sisificamente. Maquinalmente esse personagem trabalha dia após dia sem mais ouvir-o-outro e sem mais ser-ouvido-pelo-outro, encandeando-se uma triste equação do silêncio e da anulação.

A terceira obra, que fecha essa trilogia do refugo humano é Carvão Animal. O romance conta a estória do bombeiro Ernesto Wesley e seu irmão Ronivon, funcionário do crematório da fictícia e cinzenta cidade de Abalurdes. Assombrados por uma tragédia do passado, que ao longo da narrativa os persegue, esses dois irmãos lidam com o fogo: um para combatê-lo e o outro para utilizá-lo para apagar os vestígios da existência. Mais uma vez nos deparamos com uma espécie de brutalização humana que não permite a menor possibilidade de sonhar com uma saída reparatória e redentora:

Ernesto Wesley é um brutamontes de ombros largos, voz grave e queixo quadrado, porém tudo isso se torna pequeno caso se repare em seus olhos. São olhos profundos, de cor negra e de intenso brilho. Mas não é um brilho de alegria, senão do fogo admirado e confrontado diversas vezes. Quando se atravessa a barreira de fogo que ilumina o seu olhar, não há nada além de rescaldo. Sua alma abrasa e seu hálito cheira a fuligem (MAIA, 2011, p. 18).

O fogo se converte em um signo mortuário que se alimenta dos corpos. Na rotina de carbonizar os mortos, Ronivon aprende a reconhecer como a gordura funciona como combustível e como as extremidades se contorcem e encolhem. É com o extremo calor que tudo "o que já foi humano parece voltar-se para o lado de dentro" (MAIA, 2011, p. 23). Com Ernesto Wesley, completa-se o quadro das monstruosidades sensoriais: Erasmo Wagner não repara, Alandelon não escuta, Ernesto Wesley não sente. $\mathrm{O}$ bombeiro não sente o fogo queimar na sua pele, pois possui um raro tipo de doença, analgesia congênita, que se configura como uma deficiência estrutural do sistema nervoso periférico central. Isso o "torna insensível ao fogo, a facadas e espetadas" (MAIA, 2011, p. 16), adaptando-o a dor que seria vivenciada todos os dias. Novamente evidenciamos um homem-besta que na sua condição de humano-coisa deve aturar/naturalizar as mais extremadas situações terrenais. Ronivon, por sua vez, foi educado, desde cedo, pelo calor dos corpos dos mortos. O calor gerado pelos fornos crematórios passa por uma tubulação ligada a um conversor termoelétrico, que transforma calor em energia elétrica. Ele sabe como poucos que os mortos carbonizados ajudam a suprir parte da energia usada tanto no crematório quanto no hospital que fica a um quilômetro dali, além de alguns estabelecimentos comerciais da redondeza.

Nesse estranho ciclo entre morte-calor-vida, o funcionário do crematório orquestra as filas dos mortos, "principalmente os indigentes", para serem "cremados no Colina dos Anjos e seu calor transformado em energia para abastecer os vivos" (MAIA, 2011, p. 69). Habitante do subterrâneo, Ronivon tem uma cor pálida que o transforma num tipo de morto-vivo, acostumado aos ratos e ao espetáculo da cremação no qual a boca do morto se escancara, fazendo os dentes saltar e o rosto murchar como se fosse um grito de horror. E resta a esse operário do matar-a-morte a atividade de passar um detector de metais portátil sobre o peito mirrado antes de fechar o caixão. Sem qualquer resquício de emoção, o trabalhador mensura o tempo de transformação da carne em carvão animal através da estória de cada morto:

O velho que morreu de complicações no pulmão. Fumou por quarenta e sete anos. Praticamente, o velho estava sendo cremado ao poucos durante todo esse tempo. Dos pulmões restou apenas um pedaço do lado esquerdo. Sua pele amarelenta é extremamente enrugada, parecendo uma pele de cobra. Os vincos são profundos. As pontas dos dedos são de tonalidade caramelo, manchado pelo fumo. Mas um corpo assim tão magro e ressecado levará mais tempo para queimar. O caixão seguinte é uma mulher de quarenta e oito anos. Rosto bonito. Cabelos lisos e pretos. Morreu de infarto, pouco comum às mulheres. $\mathrm{Na}$ ficha de controle ainda há seis corpos a serem cremados neste dia (MAIA, 2011, p. 24).

No interior dessa insólita "carvoaria" de Ronivon, os corpos menos saudáveis são aqueles que mais resistem ao fogo, enquanto os mais debilitados queimam lentamente numa espécie de resistência ao tornar-se pó. Mas o operário das cinzas tem uma convicção quanto aos corpos, sadios ou não, que o acompanham: "no fim tudo o que resta são os dentes" (MAIA, 2011, p. 9). É preciso cuidar dos dentes porque eles permitem identificar a sua dignidade, preservando-os será possível reconstruir o indivíduo, pois, quando o corpo carboniza, "sua profissão, dinheiro, documentos, memória, amores não servirão para nada" (MAIA, 2011, p. 9). Afinal, no fim apenas sobram os dentes. Essa parece ser uma excelente metáfora para finalizar uma reflexão sobre esses seres-refugo que constituem a trilogia do homem comum. Dentes: presas que mordem e mastigam as sobras do sujo cotidiano, numa digestão empobrecida. Dentes: lancinantes e perfurantes armas dos cães-de-rinha, que mutilam para sobreviver. Dentes: ausentes nas bocas fétidas de Edivardes e Erasmo Wagner, que pastam os grudes de lixo. Dentes: vestígios paleontológicos de uma espécie de ser humano que habita as áreas abjetas, porcas e invisíveis da nossa sociedade. 


\section{Referências}

AGAMBEN, Giorgio. O que é o contemporâneo? E outros ensaios. Chapecó: Argos, 2010.

BARTHES, Roland. Como viver juntos. São Paulo: Martins Fontes, 2003.

COMPAGNON, A. Os antimodernos. De Joseph De Maistre a Roland Barthes. Belo Horizonte: Editora UFMG, 2011.

ITURBE, Antonio G. A bibliotecária de Auschwitz. Rio de Janeiro: Agir, 2014.

LIPOVETSKY, Gilles. Os tempos hipermodernos. São Paulo: Barcarolla, 2004.

MAIA, Ana Paula. Carvão animal. Rio de Janeiro: Record, 2011.

MAIA, Ana Paula. Entre rinhas de cachorros e porcos abatidos. Rio de Janeiro: Record, 2009.
MCCRACKEN, Scott. Pulp: Reading popular fiction. Manchester: Manchester University Press, 1998.

RESENDE, Beatriz. Contemporâneos: expressões da literatura brasileira do século XX. Rio de Janeiro: Casa da Palavra, 2008.

SARAMAGO, José. Ensaio sobre a Cegueira. São Paulo: Companhia das Letras, 1995.

SPIVAK, Gayatri Chakravorty. Pode o subalterno falar? Belo Horizonte: UFMG, 2010.

VALÉRY, Paul. Monsieur Teste. São Paulo: Ática, 1997.

Recebido: 01 de junho de 2016

Aprovado: 15 de junho de 2016.

Contato: ricardo.barberena@pucrs.br 